\title{
Administrative Assistants as Interruption Mediators
}

\author{
Laura A. Dabbish, Ryan S. Baker \\ Human-Computer Interaction Institute \\ Carnegie Mellon University \\ 5000 Forbes Ave., Pittsburgh, PA 15213 USA \\ \{dabbish,rsbaker\}@cs.cmu.edu
}

\begin{abstract}
When designing automated systems that make decisions about when to allow or deny interruptions, the methods of professional interruption mediators are an important source of information. Administrative assistants are, by the nature of their jobs, expert interruption mediators. They make decisions every day about whether to allow interruptions to the person they support. We have conducted a series of interviews with administrative assistants whose ability has been publicly recognized. Based on their responses, we present a production-rule model of the decision process they use when deciding whether to deliver interruptions to the person they support.
\end{abstract}

\section{Keywords}

Interruption, Administrative assistants, gatekeepers

\section{INTRODUCTION}

How should an automated system make decisions about when to allow or deny full-scale interruptions? In their work, administrative assistants routinely use a sophisticated set of heuristics to decide whether to allow interruptions (on the phone and face-to-face) [2]. They mediate the interruptibility of another individual, their supportand ${ }^{1}$, and are experts at the task. Though administrative assistants have been recognized for the important role they play in organizations [1], their role as interruption mediators has not been studied.

In this paper we present an interview study that examines the sophisticated heuristics that administrative assistants employ when making interruption decisions. We also present a production-rule model of their decision process in delivering an interruption, based on the responses from the interviews.

\section{METHOD}

Interviews were performed with six administrative assistants working at the same university, four of them full gatekeepers $^{2}$. These administrative assistants supported

\footnotetext{
1 Within this paper, we will refer to the person supported by the administrative assistant as a supportand, to generalize across all of the different roles that person may have, and to avoid terms that presuppose certain workplace hierarchies.
}

"star" faculty or deans, by managing their schedule, screening phone calls, and receiving visitors. Our focus was on expert interruption mediators, thus we recruited administrative assistants for the interviews who had been previously recognized as particularly dedicated or good at their job. Each interview lasted an hour, and took place in the participant's office when possible, to maintain the context where interruptions took place. The interviews focused on specific interruption events and the context in which they occurred.

\section{MODEL EXPLANATION}

On the basis of the responses from our interviews, we developed a first-draft model of the process that administrative assistants would use to decide whether to interrupt. In developing our model, we attempted to base it as much as was possible on direct evidence from our interviews. 22 of our 37 production rules can be directly attributed to specific statements on the part of our participants. Of the other 15, all but 6 deal with initial goalsetting or acting upon prior decisions.

It should be noted that administrative assistants have a number of different responsibilities, many of which are not covered in this model.

\section{MODEL DESCRIPTION}

This model has four main goals, illustrated in Figure 1. Both the importance of the interruption and the interruption threshold of the supportand are classified along the following four-point scale: full importance (e.g. sick child, meeting with president of university), high importance (e.g. grant proposal due in next 24 hours), routine importance (e.g. lab meeting with graduate student), low importance (e.g. colleague from another university who supportand does not know).

The supportand's interruption threshold is classified by how important an interruption would need to be for the interruption to be allowed. In determining how important an interruption is, the assistant first attempts to determine how important the interruptor is to the user. The categorization of how important a given individual is to the supportand must to some extent be learned. Different supportands have different job roles, and therefore different people with which they interact.

\footnotetext{
2 'Gatekeeper' assistants sit directly outside, or next to the faculty member they support. These assistants typically control all face-to-face and phone access to the faculty member, thus completely mediating almost all possible interruptions.
} 


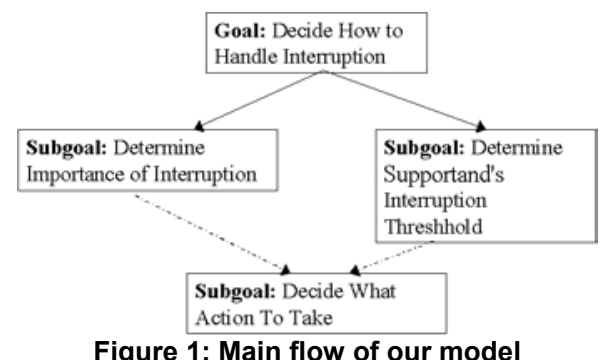

Figure 1: Main flow of our model

During our interviews, the categorizations that affected a given individual's importance varied to some degree. There were, however, certain consistent mappings across individuals, which we labeled: full importance (e.g. external personal callers such as family members, and VIPs such as the president of the university), high importance (e.g. very close colleagues such as co-authors), routine importance (e.g. colleagues, students), low importance (e.g. individuals who supportand does not know).

Evidence from the interviews suggested that the decision process used by the assistants varied for these different categories, as shown in Figure 2. Individuals of routine or low importance are asked what their business is, whereas it is generally assumed that individuals of high importance have business of high importance (skipping the "determining business" subgoal but not the "determine interruption threshold" subgoal). Individuals of full importance are given immediate access, if at all possible.

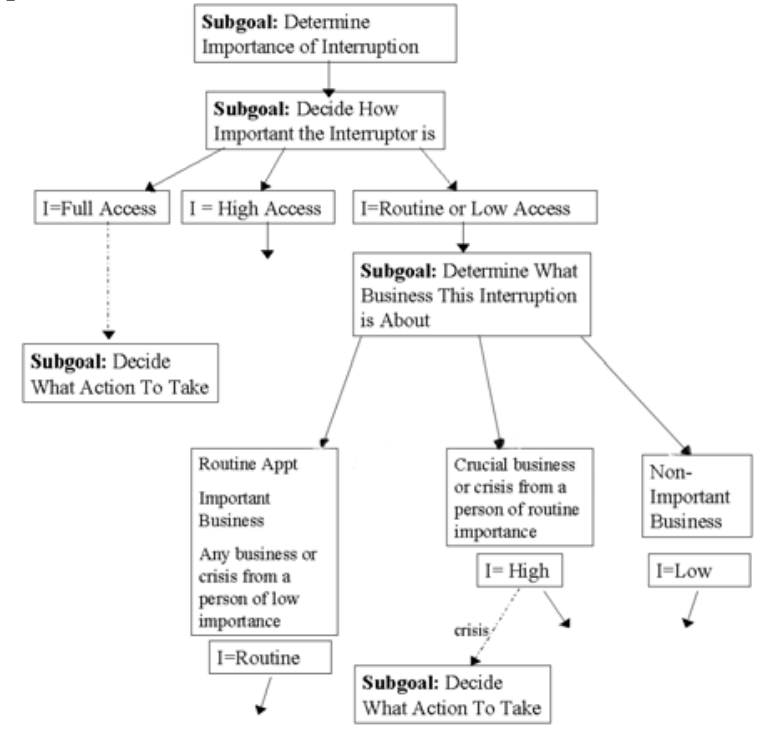

Figure 2: How important is this interruption?

The calculation of the importance of a piece of business is a combination of how important the business is to the interruptor combined with the importance of the interruptor. This process, shown in Figure 2, matched fairly closely to what was described in the interviews. Once the importance of a piece of business is established, the supportand's interruption threshold must be determined, as shown in Figure 3. In general, if a signal, such as a do-notdisturb sign, is given to the assistant, only "Full Access" interruptions are allowed.

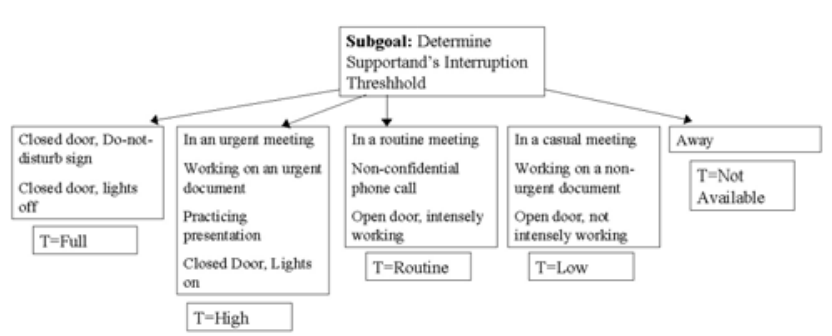

Figure 3: How interruptible is the supportand?

If the supportand is in a meeting or on the phone, the assistant uses prior knowledge about the nature and confidentiality of the meeting in determining its importance. From the interview responses, three categories of meetings emerged: high importance (meetings which were called on very short notice or involved very important individuals), routine importance (routinely scheduled meetings), and low importance (casual, unscheduled meetings).

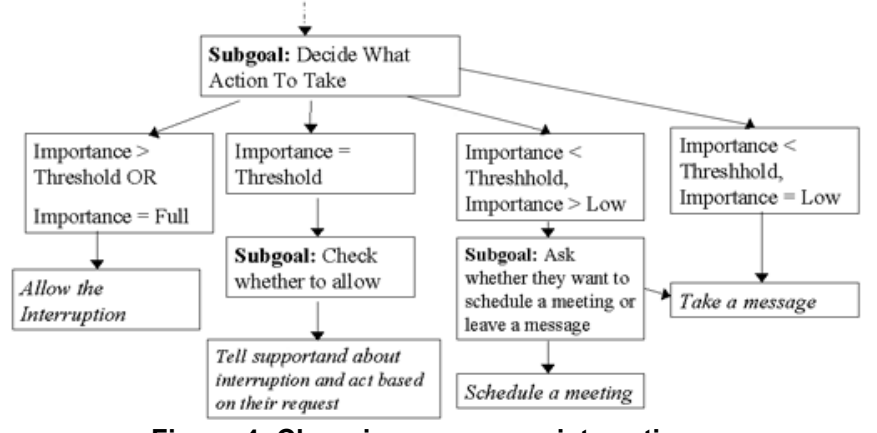

Figure 4: Choosing an appropriate action

If the supportand is working alone, the assistant looks into the supportand's door to gain additional information. When the door is closed, then the supportand's threshold is high. Finally, once the importance of the interruption and the supportand's current task are determined, the assistant can decide upon a course of action. (shown in Figure 4)

\section{CONCLUSIONS AND FUTURE WORK}

What we have learned about the processes and information administrative assistants use in making an interruption decision will aid in building systems more sensitive to the actual needs of the user. We are currently in the early stages of a set of studies to validate this model, both by comparison to administrative assistants' actual decisions, and the decisions their supportands would prefer. In this study, both administrative assistants and supportands will be presented with scenarios culled from our interviews and subsequently asked what course of action they would take/prefer. Data from their responses will then be compared to our model's predictions.

\section{ACKNOWLEDGEMENTS}

We would like to thank Sara Kiesler, Bob Kraut, and Ken Koedinger for helpful suggestions and assistance.

\section{REFERENCES}

1. Demongeot, C.A. (1986). Secretaries: The unrecognized members of the management team. Training \& Development Journal, 40, 28-29.

2. Patterson, M., Nonverbal behavior: A functional perspective, NewYork: SpringerVerlag, 1983. 